\title{
An exploratory study of a large, synchronous, multilingual electronic meeting
}

\author{
Mahesh Vanjani, Texas Southern University, mahesh.vanjani@tsu.edu \\ Jamison Posey, University of Mississippi,jposey@bus.olemiss.edu \\ Milam Aiken, University of Mississippi,maiken@bus.olemiss.edu
}

\begin{abstract}
In prior studies of large, multilingual, electronic meetings, results showed that group members were able to exchange comments in many languages effectively and efficiently. However, prior studies have had several limitations including inauthentic comments, inaccessible software, and differences in user interfaces. Further, it is not clear how large a multilingual electronic meeting can be and still remain effective and efficient. In this study, 54 students communicated in 45 languages simultaneously using Microsoft Live Translator. Results showed that as in previous studies, participants reported that the system supported the multilingual meeting well. However, with the synchronous interface, group members could be overwhelmed as more comments arrive quickly.
\end{abstract}

Keywords: multilingual, electronic meeting, synchronous

\section{Introduction}

Groups with members speaking different languages can now meet electronically with automatic translation to effectively and efficiently support communication. Just as electronic meetings increase the productivity of monolingual groups (Dennis, et al., 1990a), the effect on multilingual groups can be even greater with the aid of automatic translation. In traditional, oral meetings such as those used in the United Nations, speakers take turns and interpreters convey the information into each of the six official languages. However, this takes a tremendous amount of time. In an electronic meeting, all participants can type comments simultaneously and anonymously while everything is recorded in a transcript, resulting in time savings, more satisfaction with the process, and, more candid ideas (Pepper, et al., 2011). With simultaneous machine translation of typed comments, there is no need for human interpretation, and many more languages can be supported inexpensively and quickly, but perhaps with some decrease in accuracy (Williams, et al., 2012).

Group members could use one of many chat programs to support a multilingual meeting by manually copying and pasting translations from Google Translate, for example, but few participants want to make the effort (Aiken \& Park, 2009). Instead, these meetings have relied upon dedicated software with automatic translation. Many studies have investigated how multilingual groups can use this electronic meeting software (Vanjani, 2012), but much of the research has had limitations. In this study, we attempt to address some of these problems by using different software and meeting configuration. 


\section{Literature Review}

Early studies of multilingual, electronic meeting systems involved students fluent in English (due to samples of convenience) typing comments and evaluating translations from text entered by the facilitator in other languages (Aiken, et al., 1992). Thus, they were not truly representative of multilingual meetings. Perhaps the first multilingual, electronic meeting (MEM) using native or fluent speakers was conducted in 1994 with three Spanish and six English members (Aiken, et al., 1994b). Later studies included meetings with one German, one French, and two English speakers (Aiken, et al., 2002), two English and two Chinese (Aiken, et al., 2003), and four Korean and 11 English (Aiken, et al., 2011a). Perhaps, the most linguistically diverse study used groups ranging from four to 25 with a mixture of Arabic, Chinese, English, French, German, Hindi, Indonesian, Malay, and Spanish speakers (Aiken, et al., 2011b). Results of this study showed that although not all translations were understood clearly, the participants considered the accuracies to be adequate and they were satisfied with the overall process. In all of these meetings, the comments were authentic, originating from the participants themselves, in their chosen language.

Other studies have focused on the effect of size on electronic meetings. Dennis, et al., 1990b showed that in a monolingual electronic meeting environment, larger groups generated more ideas of greater quality and were more satisfied than smaller groups. Another study (Aiken, et al., 1994a) showed that 48 people typing comments face-to-face outperformed equivalently sized oral groups. A third study (Aiken \& Wong, 2003) with group sizes between two and 14 showed that the full benefits of electronic meetings are achieved once the number of participants reaches about six. A fourth study (Lindblom, et al., 2009) with two large oral meetings (group sizes of 38 and 37) and two electronic meetings (group sizes 33 and 35) showed that electronic meeting participants were able to communicate better with less fear of criticism and generated more total comments, relevant comments, and words per comment.

In a multilingual environment, it is not clear how large a meeting can be and still remain productive. The addition of language translation makes the relative disparity between electronic and oral meetings even greater as the complexity of interpreting grows with more participants and languages added. For example, there are six language-pair combinations with three languages (e.g. German to French, French, to German, English to German, etc.), 30 different combinations with six languages, and 132 combinations with 12 languages. It would be nearly impossible to find human interpreters capable of translating simultaneously and accurately, cheaply, and immediately for so many language pairs (Aiken, 2009).

Early multilingual meeting studies had relatively few group members, but in one experiment (Aiken, et al., 2010b), a group of 40 students used a MEM in a face-to-face environment with 40 languages. Physical separation might not matter, however, as one study (Aiken \& Vanjani, 1997) showed that monolingual groups in two locations communicating as one were more satisfied with the meeting and generated more comments than a face-to-face group with the same number of participants. Yet another study (Aiken, 2000) showed that large electronic meetings composed of sub-groups generated more, unique, quality ideas per person. In one MEM (Aiken, et al., 2011c), a group of 32 students in three locations exchanged comments in eight languages, synchronously. The participants thought the system was easy to use and useful, estimated that an equivalent oral meeting with a human interpreter would have taken about five times longer, and believed their comprehension of translations met the minimum standard they required.

In a more recent study (Posey \& Aiken, 2015), 66 students used a MEM with 66 languages. However, like the 2010 study, they were given previously translated comments to enter into the system (they were not authentic), and they evaluated the translations back into English. Results showed a high rate of comprehension (89\%), and there was no significant difference between this reported rate and the students' stated required rate or understanding. Because the comments were prepared for the participants, there were 


\section{Issues in Information Systems}

Volume 22, Issue 2, pp. 96-105, 2021

no mistakes in the text that was simply copied into the meeting system, greatly decreasing the likelihood of translation errors (Aiken, et al., 2010a).

Besides comment authenticity, group size, and physical distribution, the user interface might be a factor in the performance of a multilingual meeting system. The vast majority of multilingual electronic meeting studies have used an academic system combining a plain Web-based chatroom with automatic translation via Google Translate (Aiken \& Ghosh, 2009). However, a few studies have used different systems concentrating on Asian languages (e.g., Lim \& Yang, 2008; Ogura, et al., 2004; Yamashita \& Ishida, 2006), and in the past few years, Google and Microsoft have introduced their own online multilingual chatroom software.

The custom-designed system linked to Google Translate is completely anonymous and asynchronous, but Google's and Microsoft's systems are synchronous (you cannot see comments entered before joining the conversation) and pseudonymous (real or fictitious names are ascribed to each comment). One study (Aiken \& Rebman, 2000) using non-anonymous, pseudo-anonymous, and anonymous treatments in monolingual electronic meetings found no significant difference in the number of comments generated per person and meeting process satisfaction when discussing a non-controversial topic. The level of anonymity could affect how candid the ideas are in a contentious meeting, but flaming could also rise if participant names are not ascribed to the text (Alonzo \& Aiken, 2004).

Finally, the Google and Microsoft user interfaces are more like instant messaging apps found on mobile phones with high-end graphics rather than just plain text. A prior study (Aiken \& Park, 2020) comparing the academic system with Microsoft's showed there were no significant differences between the two in terms of perceived translation accuracy, usefulness, ease of use, and design quality. Again, users' comments were not authentic, the group sizes were not very large, and the system was not stress-tested with comment overload.

\section{Microsoft Translator Live}

Microsoft Translator Live (https://translator.microsoft.com/) was developed in 2016 to provide instantaneous translation through typing or speech. As of April 2021, the software supports 66 languages, and more are continually added. To use the software, a host must login to start a meeting. The site provides the host a meeting code which is then shared with the selected group members. Each participant selects his or her preferred language and the conversation is shown via bubbles with real or fictitious names (e.g., "user10") ascribed to each comment. Figure 1 illustrates how a group member can converse using Spanish. That is, some of the comments could have been written in Spanish, while others were written in any of the other 65 languages. However, everything is shown in Spanish, including instructions on how to use the software.

Up to 500 people can converse simultaneously using Android, iOS or Windows devices for up to four hours. The host can save a transcript at the end of the meeting, but a prior conversation cannot be uploaded. That is, group members see only live conversation; there are no asynchronous discussions as were available with the academic system used in many other studies. Also, perhaps most importantly, as mentioned, the dialog appears as 'speech bubbles' constantly, perhaps distracting the group member with their frequency. With the academic system, users could choose when to see others' comments. The academic system powered by Google Translate provided support for more languages (103), allowed anonymous comments, had no time limits, and had, theoretically, no upper limit for group size. 


\section{Issues in Information Systems}

Volume 22, Issue 2, pp. 96-105, 2021

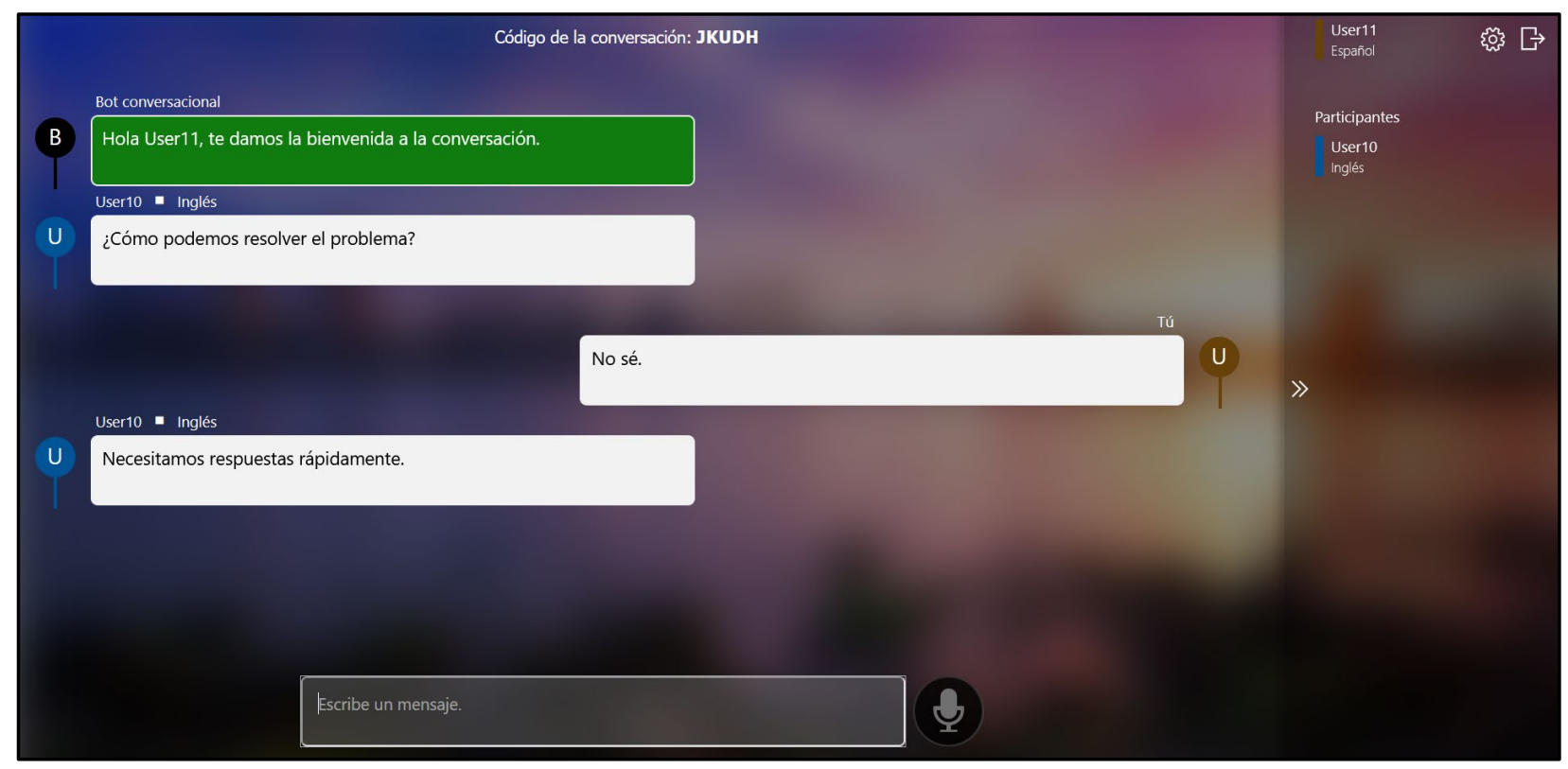

Figure 1: MS Live Translator Sample Screen Showing Comments in Spanish

Up to 500 people can converse simultaneously using Android, iOS or Windows devices for up to four hours. The host can save a transcript at the end of the meeting, but a prior conversation cannot be uploaded. That is, group members see only live conversation; there are no asynchronous discussions as were available with the academic system used in many other studies. Also, perhaps most importantly, as mentioned, the dialog appears as 'speech bubbles' constantly, perhaps distracting the group member with their frequency. With the academic system, users could choose when to see others' comments. The academic system powered by Google Translate provided support for more languages (103), allowed anonymous comments, had no time limits, and had, theoretically, no upper limit for group size.

\section{Experiment}

To address some of the limitations in previous multilingual studies, we used MS Translator Live rather than the Google system (ClickMeeting) because the latter system has a limited trial period and is not quite as easy to use. In order to test as many languages as possible, a total of 54 students ( 24 male) at a Business school in the southern United States used MS Translator Live to communicate in 45 of the 66 supported tongues: Bulgarian, Chinese (Simplified), Chinese (Traditional), Czech, Danish, Dari, Dutch, English, Fijian, Finnish, French, Haitian Creole, Hebrew, Hindi, Hmong Daw. Icelandic, Inuktitut, Irish, Japanese, Kannada, Kazakh, Klingon, Korean, Kurdish (Central), Kurdish (Northern), Lithuanian, Malagasy, Malay, Norwegian, Odia, Pashto, Persian, Portuguese (Brazil), Romanian, Russian, Samoan, Serbian, Slovak, Spanish, Swahili, Swedish, Telugu, Ukrainian, Urdu, and Vietnamese. All of the students were native or fluent English speakers, and they were assigned a language and a pseudonym, e.g. 'User 21 ' to discuss what they liked and didn't like about online learning, a teaching method which was taking place in many universities across the country.

Since they were not proficient in their assigned languages (except English), they were told to think of a comment, and then use Microsoft Translator (shown in Figure 2) to get the translation. Then, they copied and pasted the text into MS Live Translator. 


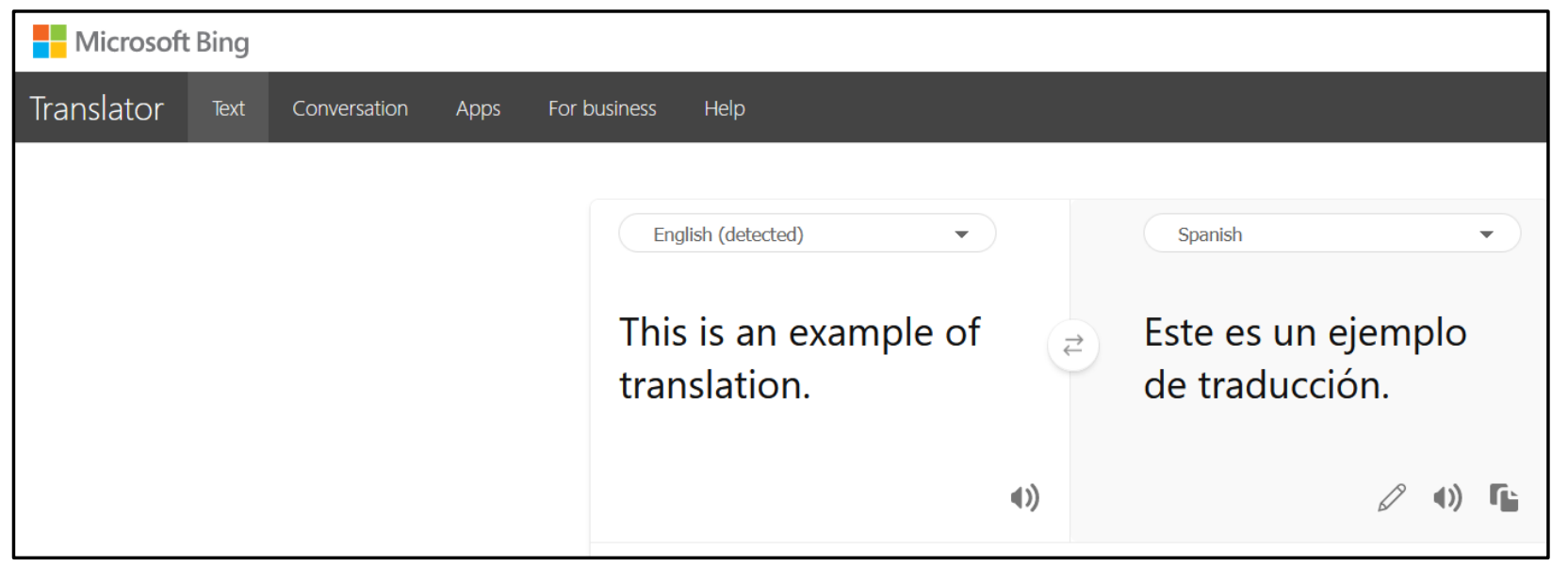

Figure 2: Microsoft Translator Sample Screen Showing Translation from English to Spanish

After the meeting, the students answered the following questions using a 7-point scale from $1=$ strongly disagree to $7=$ strongly agree:

1. (easy) The multilingual meeting system was easy to use.

2. (clear) The functionality of the meeting system was clear.

3. (quick) I learned how to use the multilingual meeting system quickly.

4. (reuse) I would use this system in a multilingual meeting.

5. (benefit) A multilingual meeting could benefit from this system.

6. (many) There were too many people in this meeting.

7. (overload) It was difficult to keep up with all of the comments written in this meeting.

8. (accurate) As far as I know, the comment I entered was accurately translated.

In 10 minutes, the 54 participants typed 72 comments, roughly 0.13 comments per minute per person. This was well below the average of seven monolingual electronic meeting studies that showed 0.38 comments per person per minute (Aiken and Vanjani, 2002), probably due to the added difficulty of copying and pasting translations. In addition, the 2002 study was based on the asynchronous, custom multilingual system in which participants chose when to read comments. Using MS Live Translator, comments continually appeared on the screen, perhaps distracting the group members. That is, group members might have felt compelled to read new comments as they appeared rather than waiting to read them all together every few minutes.

Table 1: Summary of Variables

\begin{tabular}{|l|c|c|c|c|c|c|c|c|}
\hline & easy & clear & quick & reuse & benefit & many & overload & accurate \\
\hline Mean & 5.89 & 5.96 & 6.06 & 6.07 & 6.17 & 3.56 & 4.13 & 6.15 \\
\hline Std Dev & 1.16 & 1.45 & 1.19 & 1.18 & 1.09 & 1.76 & 1.69 & 1.29 \\
\hline Min & 3 & 1 & 3 & 3 & 2 & 1 & 1 & 1 \\
\hline Max & 7 & 7 & 7 & 7 & 7 & 7 & 7 & 7 \\
\hline
\end{tabular}

Table 1 shows means and standard deviations for the survey variables, and only 'many' and 'overload' were not significantly different from a median value of 4 at $\alpha=0.05$. That is, group members thought the system was easy to use, the functionality was clear, and easy to learn. They would be willing to use the system again and thought the translations were accurate. However, they were unsure if there were too many 


\section{Issues in Information Systems}

Volume 22, Issue 2, pp. 96-105, 2021

people or too many comments, perhaps because of the speech bubbles constantly appearing on the screen. An average of 7.2 bubbles appeared before each user each minute (one every 8.3 seconds), possibly distracting or even annoying the students. Future research will investigate the break-even point where these interruptions become too great.

Table 2: Correlation analysis of variables

\begin{tabular}{|l|l|l|l|l|l|l|l|}
\hline & easy & clear & quick & reuse & benefit & many & overload \\
\hline clear & 0.747 & & & & & & \\
\hline & $<0.001$ & & & & & & \\
\hline quick & 0.703 & 0.591 & & & & & \\
\hline & $<0.001$ & $<0.001$ & & & & & \\
\hline reuse & 0.668 & 0.662 & 0.482 & & & & \\
\hline & $<0.001$ & $<0.001$ & $<0.001$ & & & & \\
\hline benefit & 0.579 & 0.443 & 0.384 & 0.750 & & & \\
\hline & $<0.001$ & 0.001 & 0.004 & $<0.001$ & & & \\
\hline many & -0.312 & -0.362 & -0.196 & -0.303 & -0.314 & & \\
\hline & 0.022 & 0.007 & $\mathbf{0 . 1 5 6}$ & 0.026 & 0.021 & & \\
\hline overload & -0.261 & -0.213 & -0.125 & -0.213 & -0.297 & 0.356 & \\
\hline & $\mathbf{0 . 0 5 6}$ & $\mathbf{0 . 1 2 3}$ & $\mathbf{0 . 3 3 6}$ & $\mathbf{0 . 1 2 3}$ & 0.029 & 0.008 & \\
\hline accurate & 0.476 & 0.424 & 0.338 & 0.462 & 0.368 & -0.153 & 0.137 \\
\hline & $<0.001$ & 0.001 & 0.012 & $<0.001$ & 0.006 & $\mathbf{0 . 2 6 9}$ & $\mathbf{0 . 3 2 2}$ \\
\hline
\end{tabular}

Bold values indicate $p$ values above the significance value of $\alpha=0.05$. (not significant)

Table 2 shows that, as expected, there was a significant, positive correlation among ease of use, clear function, and learning quickness. Further, those who thought the system functioned well were more likely to believe they would reuse it and the system would benefit a multilingual meeting. Those who were overwhelmed by comments didn't think the system would benefit a multilingual meeting and believed there were too many people in the meeting. They also tended to think the translations were less accurate.

Appendix 1 shows sample comments typed by the group. As stated, most students believed their comments were translated accurately. A review of the transcript shows that all of the text was generally understandable, but some had grammatical or word choice errors. For example, "I didn't like online lessons because I wanted to go to class in someone" and "I didn't want to not be able to interact with other students." were a little confusing, but we don't know if the problems occurred because of mistakes the students made typing the comments in English, the first manual translation, or the translation provided by MS Live Translator.

\section{Conclusion}

As far as we know, this is the first study of a large group using MS Live Translator with authentic comments (comments the participants thought of themselves). Like previous studies using an asynchronous, anonymous, text-based interface, group members thought the system was easy to learn and useful for a multilingual meeting, but it is not clear if the group size can go much larger than 54 using the system because of the frequent speech bubbles that appear, possibly overwhelming the participants. All of the responses to the survey were significantly positive except for the two that reflected on this latter item, i.e., "There were too many people in this meeting." and "It was difficult to keep up with all of the comments 


\section{Issues in Information Systems}

Volume 22, Issue 2, pp. 96-105, 2021

written in this meeting." Future studies should investigate even larger groups using this software, as well as Google's ClickMeeting.

There are several limitations with the study. First, there was only one group meeting with no comparison group, due to a limitation in the sample of convenience. Ideally, multiple, large meetings should be used to test at least two different systems with the same time limit and topic. Also, due to the sample size limit, we were not able to use all of the 66 languages provided by the system. Some translations might be more or less accurate depending upon what languages are used. Finally, studies should focus on large meetings using actual groups speaking many languages, but it is very difficult to arrange this, especially for synchronous discussions.

\section{References}

Aiken, M. (2000). Brainwriting in virtual legislative sessions. Journal of International Information Management. 9(1), 11-21.

Aiken, M. (2009). Transterpreting multilingual electronic meetings. International Journal of Management \& Information Systems (IJMIS), 13(1), 35-46.

Aiken, M., Balan, S., Vanjani, M., and Garner, B. (2010a). The effect of comment errors in multilingual electronic meetings. Communications of the International Information Management Association. 10(4), 49-60.

Aiken, M. \& Ghosh, K. (2009). Automatic translation in multilingual business meetings. Industrial Management \& Data Systems. 109(7), 916-925.

Aiken, M., Martin, J., Paolillo, J., and Shirani, A. (1994a). A group decision support system for multilingual groups. Information and Management, 26, 155-161.

Aiken, M., Martin, J., Reithel, B., Shirani, A., and Singleton, T. (1992). Using a group decision support system for multicultural and multilingual communication. Proceedings of the $23^{\text {rd }}$ Annual Meeting of the Decision Sciences Institute, 2, November, San Francisco, CA, 792-794.

Aiken, M. \& Park, M. (2020). A comparison of two multilingual meeting systems. International Journal of Computer and Technology, 20, 38-44.

Aiken, M. \& Park, M. (2009). Machine translation in a multilingual electronic meeting. Journal of International Technology and Information Management 18(3/4), 395-408.

Aiken, M., Park, M., and Lindblom, T. (2011a). A comparison of oral and electronic bilingual meetings, Proceedings of the 42nd Annual Meeting of the Decision Sciences Institute, Boston, MA, November 19-22.

Aiken, M., Park, M., and Lindblom, T. (2010b). Integrating machine translation with group support systems. International Journal of Business and Management. 5(5), 25-35.

Aiken, M. \& Rebman, C. (2000). The effect of anonymity on electronic meetings. Journal of International Information Management, 9 (2), 43-52. 


\section{Issues in Information Systems}

Volume 22, Issue 2, pp. 96-105, 2021

Aiken, M., Rebman, C., Vanjani, M., and Robbins, T. (2002). Meetings without borders: A multilingual Web-based group support system. Proceedings of the America's Conference on Information Systems, August 9-11, Dallas, TX.

Aiken, M. \& Vanjani, M. (1997). A comparison of synchronous and virtual legislative session groups faced with an idea generation task. Information \& Management. 33(1), 25-31.

Aiken, M. and Vanjani, M. (2002). A mathematical foundation for group support system research. Communications of the International Information Management Association, 2(1), 73-83.

Aiken, M., Vanjani, M., Martin, J., Young, C., and Govindarajulu, C. (1994b). Experiences with a bilingual group decision support system. International Business Schools Computing Quarterly, 6(1), 4-9.

Aiken, M., Wang, J., Gu, L., and Paolillo, J. (2011b). An exploratory study of how technology supports communication in multilingual groups. International Journal of e-Collaboration, 7(1), 17-29.

Aiken, M., Wang, W., and Vanjani, M. (2003). Automatic comment translation in a Chinese-English electronic meeting. Proceedings of the $34^{\text {th }}$ Annual Southwest Decision Sciences Institute Conference (SWDSI), March 6-8, Houston, Texas, 30-34.

Aiken, M., Wee, J., and Vanjani, M. (2011c). A Web-based multilingual meeting system: Breaking the language barrier. Business Research Yearbook. 18(1), 71-76.

Aiken, M. \& Wong, Z. (2003). The effect of group size on electronic idea generation. International Journal of Human Resources Development and Management, 3(3), 265-274.

Alonzo, M. \& Aiken, M. (2004). Flaming in electronic communication. Decision Support Systems, 36(3), 205-338.

Dennis, A., Nunamaker, J., Vogel, D. (1990a). A comparison of laboratory and field research in the study of electronic meeting systems. Journal of Management Information Systems, 7(3), 107-135.

Dennis, A., Valacich, J., and Nunamaker, J. (1990b). An experimental investigation of the effects of group size in an electronic meeting environment. IEEE Transactions on Systems, Man, and Cybernetics, 20(5), 1049-1057.

Lim, J. and Yang, Y. (2008). Exploring computer-based multilingual negotiation support for English Chinese dyads: Can we negotiate in our native languages? Behaviour \& Information Technology, 27(2), 139-151.

Lindblom, T., Aiken, M., \& Vanjani, M. (2009). Electronic facilitation of large meetings. Communications of the International Information Management Association, 9(3), 23-39.

Ogura, K., Hayashi, Y, Nomura, S., and Ishida, I. (2004). User adaptation in MT-mediated communication. The First International Joint Conference on Natural Language Processing, 596-601.

Pepper, W., Aiken, M., and Garner, B., (2011). Usefulness and usability of a multilingual electronic meeting system. Global Journal of Computer Science and Technology. 11(10), 35-40. 


\section{Issues in Information Systems}

Volume 22, Issue 2, pp. 96-105, 2021

Posey, J. and Aiken, M. (2015). Large-scale, distributed, multilingual, electronic meetings: A pilot study of usability and comprehension. International Journal of Computers and Technology. 14

Williams, K., Aiken, M., and Pepper, W. (2012). Multilingual meetings and the time value of accurate translations. Business Research Yearbook. 19(1), 158-165.

Vanjani, M. (2012). A review of multilingual electronic meeting research. Business Research Yearbook. $19(1), 126-134$.

Yamashita, N. and Ishida, T. (2006). Effects of machine translation on collaborative work. Proceedings of the $200620^{\text {th }}$ Anniversary of the International Conference on Computer Supported Cooperative Work (CSCW-06), November 4-8, Banff, Alberta, Canada, 515-523.

\section{Appendix}

Sample Comments Typed in Other Languages Translated to English

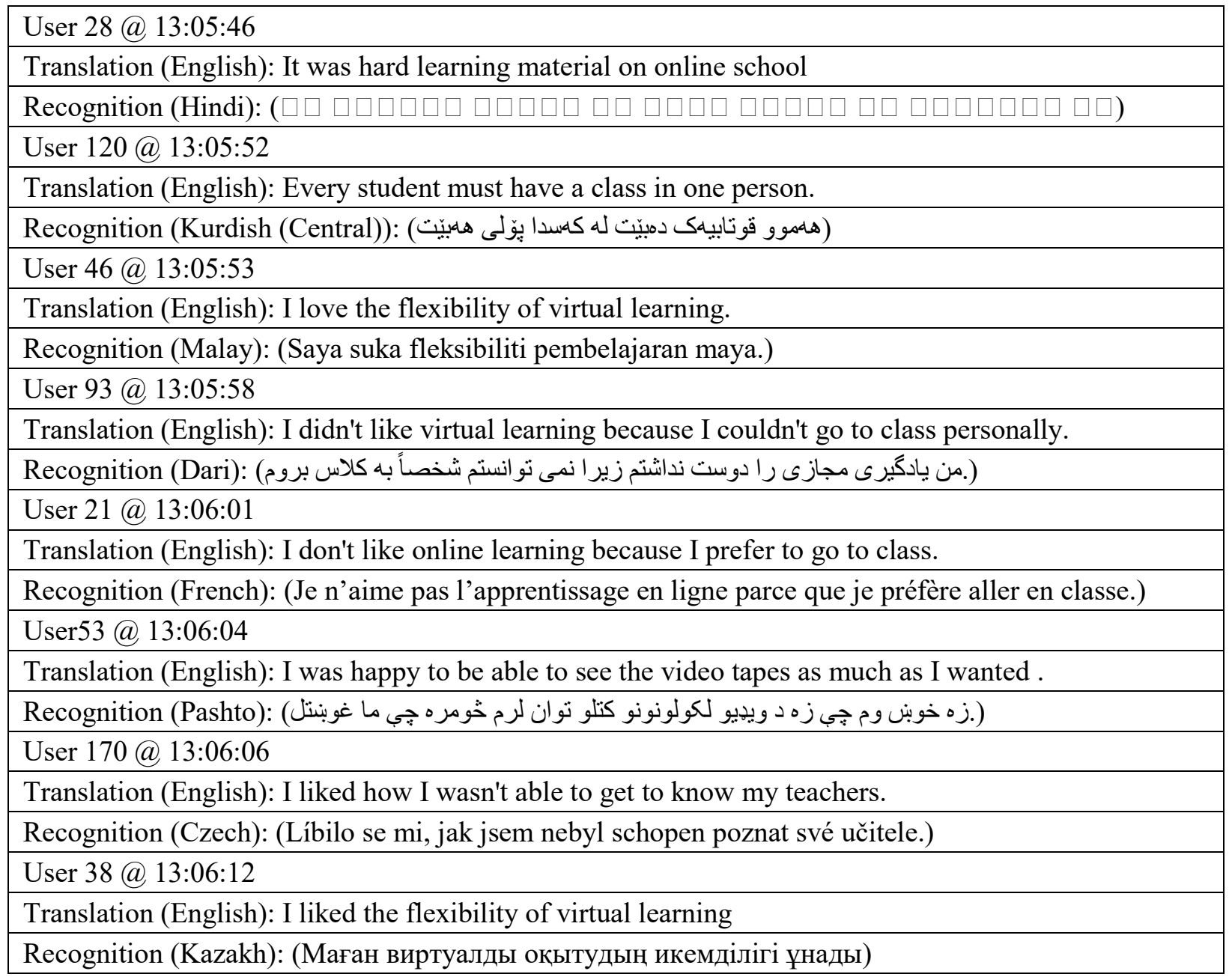




\section{Issues in Information Systems}

Volume 22, Issue 2, pp. 96-105, 2021

\begin{tabular}{|l|} 
User 203 @ 13:07:09 \\
\hline Translation (English): I don't like the lack of communication with my teachers. \\
\hline Recognition (Malagasy): (Tsy tiako ny tsy fahampian'ny fifandraisana amin'ireo mpampianatra ahy.) \\
\hline User 42 @ 13:07:09 \\
\hline Translation (English): I didn't like online lessons because I wanted to go to class in someone \\
\hline $\begin{array}{l}\text { Recognition (Kurdish (Northern)): (Min ji dersên online hez nekir ji ber ku ez dixwazim di kesek de } \\
\text { dersê diçim.) }\end{array}$ \\
\hline User 168 @ 13:07:10 \\
\hline Translation (English): I like to be able to do my own time work, but I prefer to learn face-to-face \\
\hline $\begin{array}{l}\text { Recognition (Chinese Traditional): (我喜歡能 叉做我自己的時間工作, 但我更喜歡面對面接觸學 } \\
\text { 習) }\end{array}$ \\
\hline User15 @ 13:07:14 \\
\hline Translation (English): I didn't like how Proctorio would ask for a password if none was needed. \\
\hline $\begin{array}{l}\text { Recognition (Dutch): (Ik vond het niet leuk hoe Proctorio om een wachtwoord zou vragen als er geen } \\
\text { nodig was.) }\end{array}$ \\
\hline User215 @ 13:07:27 \\
\hline Translation (English): I didn't want to not be able to interact with other students. \\
\hline Recognition (Portuguese (Brazil)): (Não gostava de não poder interagir com outros alunos.) \\
\hline User 123 @ 13:07:36 \\
\hline Translation (English): Schools should be reopened soon \\
\hline Recognition (Lithuanian): (Netrukus vėl turètu būti atvertos mokyklos) \\
\hline
\end{tabular}

